\title{
Quality-by-Design Approach and Optimization of Risk Factors by Box- Behnken Design in Formulation Development of Aspirin and Glycine Orally Disintegrating Tablet
}

\author{
R. Kayesh ${ }^{1}$, M. R. H. Bhuiya ${ }^{2}$, M. F. Islam ${ }^{2}$, J. A. Chowdhury ${ }^{2 *}$ \\ ${ }^{1}$ Department of Pharmaceutical Chemistry, University of Dhaka, Dhaka 1000, Bangladesh \\ ${ }^{2}$ Department of Pharmaceutical Technology, University of Dhaka, Dhaka 1000, Bangladesh
}

Received 8 February 2021, accepted in final revised form 1 June 2021

\begin{abstract}
Quality-by-design approach (QbD) was applied to develop an orally disintegrating tablet (ODT) formulation of aspirin and glycine. At first, the target quality profile and critical quality attributes (CQAs) of the product were identified. Risk assessment was accomplished by failure mode and effects analysis (FMEA) method to assess the factors having a significant effect on CQAs like disintegration time (DT), friability and assay of aspirin and glycine. Low substituted hydroxypropyl cellulose (L-HPC), croscarmellose sodium (CCS) and punch-diameter were found critical for DT and friability. The box-Behnken design was applied to optimize those 3 factors to reach a target DT of $\leq 30 \mathrm{sec}$. It was found that a punch-diameter between $8.7 \sim 9.3 \mathrm{~mm}$, CCS in a range of $4 \% \sim 5 \%$, and L-HPC in a range of $2 \% \sim 8 \%$ produced the best oral disintegrating property and reduced the risk. In summary, this work represented an excellent example of the application of QbD approach in ODT formulation development.
\end{abstract}

Keywords: Aspirin; Glycine; Risk assessment; Quality-by-design; Box-Behnken design.

๑) 2021 JSR Publications. ISSN: 2070-0237 (Print); 2070-0245 (Online). All rights reserved. doi: http://dx.doi.org/10.3329/jsr.v13i3.51952 J. Sci. Res. 13 (3), 935-950 (2021)

\section{Introduction}

Acetylsalicylic acid, commonly known as Aspirin (ASP), acts as a platelet aggregation inhibitor. There are plenty of studies that indicate the fact that ASP at low dose $(50-320$ $\mathrm{mg} /$ day) acts as an effective antithrombotic agent [1]. Thus, it reduces the incidence of myocardial infarction and death in patients with unstable angina [2]. Glycine (GLY) is an essential amino acid that has been proven to reduce gastric irritation of ASP when it is given concurrently with ASP [3,4]. It was also studied that GLY improves the solubility of ASP in water and also masks the sour taste of ASP to some extent when it is disintegrated on tong [5,6]. Consequently, ASP and GLY now a day comes up in combination as orally disintegrating tablet (ODT) in different strength (e.g., ASP $75 \mathrm{mg}+$ GLY $37.5 \mathrm{mg}$, ASP $100 \mathrm{mg}$ + GLY $45 \mathrm{mg}$ etc.). ODTs have gained much interest during

\footnotetext{
*Corresponding author: jakir@du.ac.bd
} 
the last decade due mainly to their ease of administration in patients with deglutition disorder [7-10]. Formulation of ODTs, however, has always been a great challenge as many factors can stifle the successful development of ODTs. Among those factors, taste masking of drug substance, quick disintegration time, low tablet weight, small tablet dimension, enough mechanical strength, physical stability throughout the shelf life are few to mention $[8,11]$.

In the current study, we put effort to develop a formulation of the orally disintegrating tablet of ASP 100mg and GLY 45mg by quality by design (QbD) approach following the ICH Q8 guideline. To do so, we first set the target quality profile of the product. This includes the physical and chemical attributes to meet the safety, efficacy and patient compliances for the ODT of ASP and GLY combination. Then we identified the critical quality attributes (CQA) that are needed to be within a certain limit or range to achieve the target quality. After that, through extensive literature review and justification, we selected the excipients appropriate for the current formulation development. We performed a quantitative risk assessment of the selected excipients and process parameters through the failure modes and effects analysis (FMEA) method to identify the risk factors among the excipients and process parameters that are most critical to achieving the CQAs. Last but not least, we optimized the high-risk factors (critical excipients and/or process parameters) through the design of experiments (DoE) and statistical analysis [12,13]. We applied BoxBehnken design, a type of response surface methodology (RSM) in the DoE. The developed formula also underwent a stability study to assess its chemical and physical stability throughout the shelf life.

We performed an extensive literature search for any report of ASP and GLY combination tablet in either ODT or immediate-release form, but to the best of our search, there is none. The current work is, therefore, a thorough guide and reference for the development of ODT of a combination of these two therapeutic agents in the treatment of heart disease.

\section{Materials and Methods}

\subsection{Materials}

Aspirin (potency $99.3 \%$ ), Glycine, L-HPC, CCS, microcrystalline cellulose (Type 101), pregelatinized starch, purified talc, and colloidal silicon dioxide (Aerosil-200) were a kind gift from Beximco Pharmaceuticals Limited, Bangladesh.

\subsection{Equipment}

Such equipment as a calibrated weighing machine (Radwag, Poland), 30 mesh screen, 8station compression machine (Proton Electronics, India), calibrated hardness tester (YD1, China), disintegration tester (Electrolab, India) located in the Pharmaceutical Technology lab of the University of Dhaka were used in the experiment. Accelerated stability study 
was conducted in Clima Cell Stability Chamber (Model: CLC-B2V/CLC-404, Year: 2001, manufactured by BMT Medical Technology).

\subsection{Elements of quality-by-design (QbD)}

According to ICH Q8 guideline, the quality by design approach for pharmaceutical formulation development includes such elements as quality target product profile (QTPP), critical quality attributes (CQA), identifying risk factors (drug substance, excipients and process attributes) that can have a potential effect on CQAs, optimization of risk factors by the design of experiments (DoE) and statistical analysis, and create design space to minimize the risks.

\subsubsection{Quality target product profile (QTPP)}

This is a description of all of the physiochemical attributes of the products that are needed to achieve for safety and efficacy of the ultimate product during its shelf-life on the market. QTPP elements that are typically taken into consideration are the route of administration, dosage form, dosage strength, pharmacokinetic targets, physical and chemical properties of drug substance (e.g., crystallinity, particle size distribution, salt form, etc.) and drug product (e.g., friability, dissolution, disintegration time, assay etc.), microbiology, container closing system, shelf-life, etc.

\subsubsection{Critical quality attributes (CQA)}

These are those elements of QTPP that are needed to be within a certain limit for the efficacy and safety of the product. For example, ODT tablets should disintegrate less than $30 \mathrm{sec}$, an assay of a drug substance should be within $\pm 10 \%$ of its claim, etc.

\subsubsection{Risk factors}

Drug substance properties, excipients and the process parameters that have a potential effect on CQA, meaning CQA can change significantly as a function of those factors.

\subsubsection{Risk assessment}

Initial risk assessment (qualitative) is done from previous experiences, pilot studies, literatures and references. Then, the quantitative risk of each selected excipient and process parameters is assessed by FMEA method.

\subsubsection{Design of experiments (DoE)}

From the risk assessment study, selected high-risk factors are subjected to optimization in a systematic way to find out their effect and interaction effects on the response. Depending upon the number of variables (i.e., the number of risk factors), different types 
of experiments can be applied for optimization. Scientists can choose any of the numbers of experimental designs for optimization, but there are some preferences with a number of variables to keep the number of experimental runs as few as possible. For example, if two variables are needed to be optimized, then a full factorial design with a center point is preferred. In such a case, a total 5 runs are required. But it is advisable to make three replicates at the center point leading to 7 runs in total. The Center point measures the curvature effect in the factor-response relationship. If the curvature effect is significant as indicated by the p-value, then the experiment should be augmented to response surface methodology (RSM). In such a case, another four experiments would be required, meaning 11 runs in total. If three factors are optimized simultaneously, then RSM is better than factorial design in terms of fewer runs and better prediction. For the three factors optimization experiment, Box-Behnken RSM (17 runs with 5 replicates at center point) is preferred to Central Composite RSM (20 runs with 5 replicates at center point). Four and five factors can be optimized by resolution IV and resolution $\mathrm{V}$ design which are nothing but fractional factorial designs.

\subsubsection{Statistical analysis [14]}

Analysis of Variance (ANOVA) is performed to calculate different statistical parameters like $F$-value, $p$-value, the sum of squares, degree of freedom, etc. Among those parameters, the $p$-value is the most important tool to the formulation scientist. $p$-value indicates whether or not the null hypothesis holds good. A $p$-value greater than 0.05 (or sometimes 0.1 ) indicates that the null hypothesis is true i.e., the experimental factors have no significant effect/influence on the response. A $p$-value less than 0.05 indicates the null hypothesis is rejected, i.e., factors substantially affect the response. As an important part of ANOVA, examination of residuals is accomplished. Examination of residuals indicates whether the model is adequate or not adequate.

Regression analysis is another important step in the DoE. In regression analysis, the relationship between independent variables and response is characterized quantitatively by a mathematical model. Such parameters as determination coefficient $\left(R^{2}\right)$, adjusted determination coefficient $\left(\operatorname{Adj}-R^{2}\right)$, predicted determination coefficient (Pred- $R^{2}$ ) are usually examined.

\subsubsection{Design space}

It describes the functional relationship between the risk factors and the CQAs. In a practical sense, design space gives a certain range or limit of critical excipients or process parameters within which CQAs meet their target. In other words, design space describes the range of risk factors within which the risk of impacting the CQAs is minimized or diminished. 


\subsection{Software}

The trial version of Design-Expert software (Design-Expert 10.0.8) was used to analyze the ANOVA and other statistics.

\section{Results and Discussion}

\subsection{Quality target product profile (QTPP)}

A brief target quality profile was set upon the definition of ODTs given by FDA as 'A solid dosage form containing medicinal substances which disintegrate rapidly, usually within a matter of sec, when placed upon the tongue'. FDA specified the in vitro disintegration time of ODT equal to or less than $30 \mathrm{sec}$. FDA also recommends the tablet weight be equal to or less than $500 \mathrm{mg}$. Based upon the description and recommendation of US-FDA guidance for ODT, the QTPP of current formulation development was set as shown in Table 1.

Table 1. Quality target product profile of ASP and GLY orally disintegrating tablet.

\begin{tabular}{|c|c|}
\hline Quality Attributes & Target \\
\hline Route of Administration & $\begin{array}{l}\text { Oral; intended to place on tongue and dissolve on tongue in a matter of } \\
\text { sec. }\end{array}$ \\
\hline Disintegration Time & $\begin{array}{l}\text { in vitro disintegration time of approximately } 30 \mathrm{sec} \text { or less, using } \\
\text { United States Pharmacopeia disintegration test. }\end{array}$ \\
\hline Tablet Weight & $\begin{array}{l}\text { Weight should be less than } 500 \mathrm{mg} \text {. In the current study target tablet } \\
\text { weight was } 220 \mathrm{mg} \text {. }\end{array}$ \\
\hline Mechanical Strength & $\begin{array}{l}\text { Sufficient to ensure physical integrity during manufacturing, packaging, } \\
\text { shipment and patients' handling. A friability of not more than } 1.0 \% \\
\text { would be considered to meet this target at the development stage. }\end{array}$ \\
\hline Physical Stability & $\begin{array}{l}\text { Physical integrity throughout the accelerated stability for } 6 \text { months. } \\
\text { Physical integrity would typically include retaining hardness, } \\
\text { appearance throughout the shelf life. }\end{array}$ \\
\hline Taste and Smell & Should have acceptable taste and smell throughout the shelf life. \\
\hline Chemical Stability & $\begin{array}{l}\text { Assay of ASP and GLY not less than } 90 \% \text { of initial estimation after } 6 \\
\text { months' accelerated stability would be considered to meet chemical } \\
\text { stability. }\end{array}$ \\
\hline Container & $\begin{array}{l}\text { Qualified container closing system that provides best protection against } \\
\text { moisture. Aluminum blister or High-Density Polyethylene (HDPE) } \\
\text { containers with moisture absorbent are best in this class. }\end{array}$ \\
\hline
\end{tabular}

\subsection{Critical quality attributes (CQA)}

In the current study, disintegrating time (DT), friability and assay of ASP and GLY were considered the CQA. ODTs are intended to disintegrate on the tongue within sec without any effort of chewing or aid of liquids. Therefore, rapid disintegration on the tongue is a CQA for ODT. To meet the rapid disintegration, ODTs are often manufactured with a high amount of super-disintegrating agents and with low hardness, often resulting in low physical integrity. Friability is an important indicator of physical integrity and is another 
CQA in the current case. If tablets are of low physical integrity, then they may break down during processing, transportation and handling, leading to safety and efficacy issues. There should be a balance between hardness and friability. ODTs should be manufactured with the lowest possible hardness while ensuring acceptable friability during the shelf life. A friability of not more than $1 \%$ was set as a target. Aspirin is a well-studied molecule and it has been shown to be a moisture sensitive and heat-labile molecule. Both moisture and heat facilitate its degradation to salicylic acid and acetic acid. Consequently, an assay of aspirin is an important CQA in this case. Assay of aspirin and glycine would be ensured more than or equal to $90 \%$ throughout the stability study.

\subsection{Basic formulation elements}

Basic elements of ODT tablet formulation and possible options for current development were presented in Table 2.

Table 2. Basic elements of ODT formulation and common excipients.

\begin{tabular}{ll}
\hline Functional Category & Available options of commonly used excipients \\
\hline Filler or Diluent & Microcrystalline cellulose, Starch, Lactose, Pregelatinized Starch, \\
& Mannitol, Dibasic calcium phosphate \\
Binder & Povidone, Copovidone, Hydroxy Propyl Methyl Cellulose, Hydroxy \\
& Propyl Cellulose, Low substituted HPC, Starch \\
Super-disintegrant & Sodium Starch Glycolate, Croscarmellose sodium, Crospovidone, \\
Lubricant & Magnesium stearate, Stearic acid, Purified talc, Calcium stearate, \\
Glidant & Sodium stearyl fumarate etc. \\
\hline
\end{tabular}

\subsection{Excipients selection by qualitative risk assessment}

In the quality by design, appropriate excipient selection in terms of compatibility with the drug molecule is of prime concern before the development trial. In the current study, a thorough literature search was done to find out those excipients that are best for the ODT formulation and are compatible with ASP. The selection of excipients for each category was properly justified.

\subsubsection{Filler}

Starch is a good filler with the disintegrating property but possesses poor flow property and contains a high amount of free moisture, which can facilitate hydrolysis of ASP. Native starch can be replaced by pregelatinized starch (starch 1500) which has a good flow. The high moisture content of starch 1500 could be a threat to the stability of ASP; however, literature shows that water activity is low for starch 1500 compared to other commonly used fillers, which is why starch 1500 produces ASP tablet with better stability $[15,16]$. Dibasic calcium phosphate could be a better choice, but it is abrasive in nature and needs a higher amount of magnesium stearate (at least $1 \%$ ) to avoid sticking during ejection [17]. Magnesium stearate, on the other hand, is incompatible with ASP [18-22]. 
Anhydrous lactose is a good choice for direct compression (DC) tablets, but some studies showed that it might not be a better choice in ODT as it hinders the disintegration [23-26]. Lactose monohydrate, on the contrary, aid in disintegration but its use can be limited by its moisture content and water activity which could facilitate ASP degradation [15]. In the case of microcrystalline cellulose (MCC) both moisture content and water activity are low [15]. Numerous studies prove that MCC is a binder, diluent, disintegrant, and also has some self-lubricating property [17]. MCC is broadly regarded as the filler having the best binding properties in the dry state [27]. In addition to its dry binding property also acts as a disintegrating agent due to its swelling property [25,28]. Upon this review, MCC was primarily chosen as filler during the optimization trials.

\subsubsection{Binder}

Among those binder stated in Table 1, L-HPC was best due to such facts as its dry binding capacity with anti-capping property and, more importantly, its swelling capacity which aids in disintegration [17]. L-HPC is the binder of choice in orally disintegrating tablets functioning as both binder and disintegrating agents [29,30].

\subsubsection{Super-disintegrating agent}

Disintegrating property does vary depending upon the API characteristics. Zhao and Augsburger carried out an experiment to prove that croscarmellose sodium (CCS) was most effective for reducing disintegration and improving dissolution of ASP among the three super-disintegrants [31,32]. Consequently, CCS was considered as the superdisintegrant in the current study.

\subsubsection{Lubricant and glidant}

Salts of stearates (magnesium stearate, calcium stearate, etc.) have ever been the most effective lubricant, but numerous studies proved that stearate salts react with ASP resulting in degradation of ASP into salicylic acid and acetic acid [18-22]. Many studies investigated the stability of ASP with talc and got better results [33-35]. Consequently, talc was chosen as a lubricant. Colloidal silicon dioxide was only one choice as a glidant.

\subsection{Quantitative risk assessment by FMEA}

Following the literature review, most compatible and convenient excipients that would best serve the QTPP of current development were chosen. Then the risk of each excipient on the major CQA of interest (i.e., DT) was quantitatively assessed by FMEA method. Risk assessment was done with respect to the probability of each excipient impacting DT, the degree of severity of impact and the detectability of impact. Scoring of the probability, severity and detectability was explained in Table 3. 
Table 3. Explanation of risk level of different terms in FMEA.

\begin{tabular}{|c|c|c|c|}
\hline Score & Probability of Impacting & Severity & Detectability \\
\hline 1 & $\begin{array}{l}\text { Extremely low chance of impacting } \\
\text { CQA, never happens usually }\end{array}$ & No impact on CQA & Detectable in unit operation \\
\hline 2 & $\begin{array}{l}\text { Low chance of impacting, but may } \\
\text { happen }\end{array}$ & $\begin{array}{l}\text { Some impact, but } \\
\text { reversible }\end{array}$ & $\begin{array}{l}\text { Detectable after the unit } \\
\text { operation and before end } \\
\text { product testing }\end{array}$ \\
\hline 3 & $\begin{array}{l}\text { Moderate chance of impacting and } \\
\text { frequently happens }\end{array}$ & $\begin{array}{l}\text { Moderate Impact but } \\
\text { not quality threatening }\end{array}$ & $\begin{array}{l}\text { Detectable only at end } \\
\text { product testing }\end{array}$ \\
\hline 4 & $\begin{array}{l}\text { High chance of impacting and } \\
\text { always happens }\end{array}$ & $\begin{array}{l}\text { High impact and } \\
\text { irreversible }\end{array}$ & $\begin{array}{llll}\text { Failure can never be } \\
\text { detected }\end{array}$ \\
\hline
\end{tabular}

Based upon the scoring system as stated above, quantitative risk assessment of selected excipients and process parameter was shown in the Table 4.

Table 4. Quantitative risk assessment of material attributes and process parameter on DT.

\begin{tabular}{llccccc}
\hline $\begin{array}{l}\text { Excipients/ } \\
\text { Process }\end{array}$ & Effect on DT & $\begin{array}{l}\text { Probability of } \\
\text { impacting DT }\end{array}$ & $\begin{array}{l}\text { Severity of } \\
\text { impact }\end{array}$ & $\begin{array}{l}\text { Detecta } \\
\text {-bility }\end{array}$ & RPN $^{1}$ & $\begin{array}{l}\text { Risk } \\
\text { rating }^{2}\end{array}$ \\
\hline L-HPC & $\begin{array}{l}\text { It has both binding } \\
\text { and swelling effect. }\end{array}$ & 4 & 3 & 3 & 36 & High \\
$\begin{array}{l}\text { Croscarmellose } \\
\text { Sodium }\end{array}$ & $\begin{array}{l}\text { Super-disintegrating } \\
\text { agent }\end{array}$ & 4 & 4 & 4 & 64 & High \\
MCC-101 & $\begin{array}{l}\text { Diluent and also a } \\
\text { weak disintegrant }\end{array}$ & 1 & 1 & 1 & 1 & Low \\
$\begin{array}{l}\text { Purified Talc } \\
\text { Lerosil-200 }\end{array}$ & $\begin{array}{l}\text { Lubricant } \\
\text { Glidant }\end{array}$ & 3 & 3 & 2 & 18 & Medium \\
$\begin{array}{l}\text { Higher dia increases } \\
\text { surface area and } \\
\text { decreases the DT }\end{array}$ & 4 & 2 & 1 & 4 & Low \\
DT is proportionate & 4 & 4 & 3 & 48 & High \\
to Hardness & 4 & 3 & 1 & 12 & Low \\
\hline
\end{tabular}

${ }^{1}$ RPN=Risk Priority Number. ${ }^{2}$ Note: $1 \sim 16$ represents low risk, 17 34 medium risk and 35 64 high risk

It was found that L-HPC, CCS and Punch Diameter have got high-risk ranking. Therefore, these three components were subjected to experimental design for optimization.

\subsection{Manufacturing procedure}

Each formulation in the subsequent steps was manufactured by direct compression (DC). Both ASP and GLY were first milled by passing through $0.5 \mathrm{~mm}$ mesh. Tablet weight was fixed at $220 \mathrm{mg}$ comprising such fixed weight components as $100 \mathrm{mg}$ ASP, $45 \mathrm{mg}$ GLY, purified talc $1.1 \mathrm{mg}(0.5 \% \mathrm{w} / \mathrm{w})$ and colloidal silicon dioxide $1.1 \mathrm{mg}(0.5 \% \mathrm{w} / \mathrm{w})$. LHPC and CCS varied in each formula according to the design and total weight was adjusted with diluent (MCC-101). In the preparation of each formula, at first, ASP, GLY, CCS, L-HPC and MCC-101 were dispensed and passed through 30 mesh and then mixed thoroughly for $10 \mathrm{~min}$. Then purified talc and colloidal silicon dioxide were passed 
through 40 mesh and mixed with the previous mixture for 1 min. Optimization batches were compressed at 5.5 newtons $(\mathrm{N})$ pressure and within a hardness of $6 \sim 7$ kilopond (Kp). To produce the same hardness, the upper punch position was adjusted, and compression thickness was changed from batch to batch.

\subsection{Design of experiment for optimization}

For simultaneous optimization of three-factor, a Box-Behnken design comprising 6 factorial points, 6 axial points and 5 replicates at the center point was constructed by the Design-Expert software. Experimental levels of critical factors were selected and justified based on literature and experience. Handbook of Pharmaceuticals states the usual level of $\mathrm{CCS}$ in tablets as $0.5 \% \sim 5 \%(\mathrm{w} / \mathrm{w})$ though $2 \%$ is enough in direct compression. But, as in the current case lowest possible DT is concerned, the experiment range was started with $2 \%$ lower level and $6 \%$ high level. L-HPC was tested between $2 \% \sim 10 \%$ (w/w). Punch diameter was examined between $8.0 \mathrm{~mm}$ to $10.0 \mathrm{~mm}$. These were presented in table 5 .

Table 5. Experimental and constant factors, response and its target.

\begin{tabular}{llllll}
\hline \multirow{2}{*}{$\begin{array}{l}\text { Experimental } \\
\text { factors }\end{array}$} & \multicolumn{3}{c}{ Levels of factors } & Response & $\begin{array}{l}\text { Target of } \\
\text { optimization }\end{array}$ \\
\cline { 2 - 4 } & High & Medium & Low & & DT $\leq 30$ sec (i.e., \\
L-HPC $(\% \mathrm{w} / \mathrm{w})$ & 10 & 6 & 2 & Disintegration & lower the better) \\
Punch dia $(\mathrm{mm})$ & 6 & 4 & 2 & Time & \\
Constant factors & 10 & 9 & 8 & & \\
Lubrication time & Fixed levels & & & \\
Compression force & $5.5 \mathrm{~N}$ & & & \\
Hardness & $6 \sim 7 \mathrm{Kp}$ & & & \\
Environment & $40 \% \sim 50 \% \mathrm{RH}, 20{ }^{\circ} \mathrm{C} \sim 25{ }^{\circ} \mathrm{C}$ & & \\
\hline
\end{tabular}

Each trial batch was prepared and compressed according to the random standard order created by the software to avoid system biasness and reduce the effect of lurking factors if any. During manufacturing and compression, such constant factor as mixing order, lubrication time (1min), humidity (RH $40 \% \sim 50 \%)$, temperature $\left(20{ }^{\circ} \mathrm{C} \sim 25{ }^{\circ} \mathrm{C}\right.$ ), compression force $(5.5 \mathrm{~N})$ and hardness $(6 \sim 7 \mathrm{Kp})$ were maintained at a fixed range/level for all the trials. Disintegration time was determined in $750 \mathrm{~mL}$ water, warmed at $37 \pm 0.5$ ${ }^{\circ} \mathrm{C}$ and without a disc to create sufficient discrimination among the batches. The design layout and the measured DT were shown in Table 6.

Table 6. Design layout with randomized standard order and the response (DT).

\begin{tabular}{llllll}
\hline $\begin{array}{l}\text { Standard } \\
\text { Order }\end{array}$ & $\begin{array}{l}\text { Run } \\
\text { Order }\end{array}$ & $\begin{array}{l}\text { L-HPC } \\
(\% \text { w/w })\end{array}$ & $\begin{array}{l}\text { CCS } \\
(\% \text { w/w })\end{array}$ & $\begin{array}{l}\text { Punch Dia } \\
(\mathrm{mm})\end{array}$ & $\begin{array}{l}\text { DT } \\
(\mathrm{sec})\end{array}$ \\
\hline 12 & 1 & 6 & 6 & 10 & 16 \\
16 & 2 & 6 & 4 & 9 & 19 \\
2 & 3 & 10 & 2 & 9 & 31 \\
1 & 4 & 2 & 2 & 9 & 28 \\
14 & 5 & 6 & 4 & 9 & 20 \\
17 & 6 & 6 & 4 & 9 & 19 \\
\hline
\end{tabular}




\begin{tabular}{llllll}
\hline $\begin{array}{l}\text { Standard } \\
\text { Order }\end{array}$ & $\begin{array}{l}\text { Run } \\
\text { Order }\end{array}$ & $\begin{array}{l}\text { L-HPC } \\
(\% \text { w/w })\end{array}$ & $\begin{array}{l}\text { CCS } \\
(\% \text { w/w })\end{array}$ & $\begin{array}{l}\text { Punch Dia } \\
(\mathrm{mm})\end{array}$ & $\begin{array}{l}\text { DT } \\
(\mathrm{sec})\end{array}$ \\
\hline 13 & 7 & 6 & 4 & 9 & 20 \\
3 & 8 & 2 & 6 & 9 & 22 \\
15 & 9 & 6 & 4 & 9 & 19 \\
6 & 10 & 10 & 4 & 8 & 28 \\
11 & 11 & 6 & 2 & 10 & 25 \\
7 & 12 & 2 & 4 & 10 & 17 \\
10 & 13 & 6 & 6 & 8 & 28 \\
8 & 14 & 10 & 4 & 10 & 13 \\
5 & 15 & 2 & 4 & 8 & 22 \\
9 & 16 & 6 & 2 & 8 & 32 \\
4 & 17 & 10 & 6 & 9 & 24 \\
\hline
\end{tabular}

\subsection{Statistical analysis}

ANOVA was conducted (by the Design-Expert software) to test the significance of the response surface quadratic model, which was presented in Table 7 . The significance of the experimental model and each term was assessed primarily by the $p$-value and secondarily by Fisher's ratio ( $F$-value). Experimental model and any term having a $p$-value $<0.05$ was considered statistically significant and a larger $F$-value indicates greater dispersion of response from a mean value indicating the prominent effect of factors on the response. It was found that $p$-value for the quadratic model and each main effect was less than 0.05 i.e., significant. Most of the interaction effects and square terms were also significant. Lack-of-fit was found to be insignificant ( $p$-value $>0.05$ ), meaning a good fit of the model. A large model $F$-value (149.77) also indicated the significance of the experimental model.

The polynomial regression equation for describing the correlation between the factors and response was constructed as follows:

Disintegration time $(\mathrm{DT})=19.40+0.88 \mathrm{~A}-3.25 \mathrm{~B}-4.88 \mathrm{C}-0.25 \mathrm{AB}-2.50 \mathrm{AC}-$ $1.25 \mathrm{BC}+0.80 \mathrm{~A}^{2}+6.05 \mathrm{~B}^{2}-0.20 \mathrm{C}^{2}(\mathrm{~A}=\mathrm{L}-\mathrm{HPC}, \mathrm{B}=\mathrm{CCS}, \mathrm{C}=$ Punch Dia $)$

The quality of the regression equation was assessed by determination coefficient $\left(R^{2}\right)$, adjusted determination coefficient $\left(\operatorname{Adj}-R^{2}\right)$ and predicted determination coefficient (Pred$R^{2}$ ) [Table 7]. The determination coefficient $\left(R^{2}\right)$ was found 0.99 indicating excellent fitting of the experimental data to the regression line. Adj- $R^{2}$ and Pred- $R^{2}$ were in reasonable agreement, i.e., the difference between them is less than 0.20. Adequate precision measures the signal-to-noise ratio and a ratio greater than 4 is desirable [14]. Here, adequate precision was found 41.05 , which indicated that this model could be used to precisely navigate the design space. 
Table 7. ANOVA for response surface quadratic model and regression analysis.

\begin{tabular}{|c|c|c|c|c|c|}
\hline \multicolumn{3}{|l|}{ ANOVA } & \multicolumn{3}{|c|}{ Regression analysis } \\
\hline Source & $\mathrm{df}$ & F-value & P-value & $R^{2}$ & 0.9948 \\
\hline Model & 9 & 149.77 & $<0.0001$ & Adj- $R^{2}$ & 0.9882 \\
\hline A: L-HPC & 1 & 17.77 & 0.0041 & Pred- $R^{2}$ & 0.9539 \\
\hline B: CCS & 1 & 241.43 & $<0.0001$ & Adeq-Precision & 41.05 \\
\hline C: Punch & 1 & 543.21 & $<0.0001$ & Adj- $R^{2}$ - Pred- $R^{2}$ & 0.0343 \\
\hline $\mathrm{AB}$ & 1 & 0.71 & 0.4260 & & \\
\hline $\mathrm{AC}$ & 1 & 71.43 & $<0.0001$ & & \\
\hline $\mathrm{BC}$ & 1 & 17.86 & 0.0039 & & \\
\hline$A^{2}$ & 1 & 7.70 & 0.0275 & & \\
\hline$B^{2}$ & 1 & 440.33 & $<0.0001$ & & \\
\hline $\mathrm{C}^{2}$ & 1 & 0.48 & 0.5102 & & \\
\hline Lack-of-fit & 3 & 1.39 & 0.3678 & & \\
\hline
\end{tabular}

To check model adequacy, residuals plots were constructed. Residual plots indicate whether there is an outlier in the data and thus tell about the precision of the experimental model. Normal probability plots of residuals and internally studentized residuals plots of residuals $v s$ predicted were taken into consideration as presented in Fig. 1. It was found that residuals were distributed along a straight line indicating the normal distribution of error terms. The internally studentized residuals were laid within \pm 2 value, indicating the absence of an outlier in the experimental data. These graphs indicated the adequacy of the model.
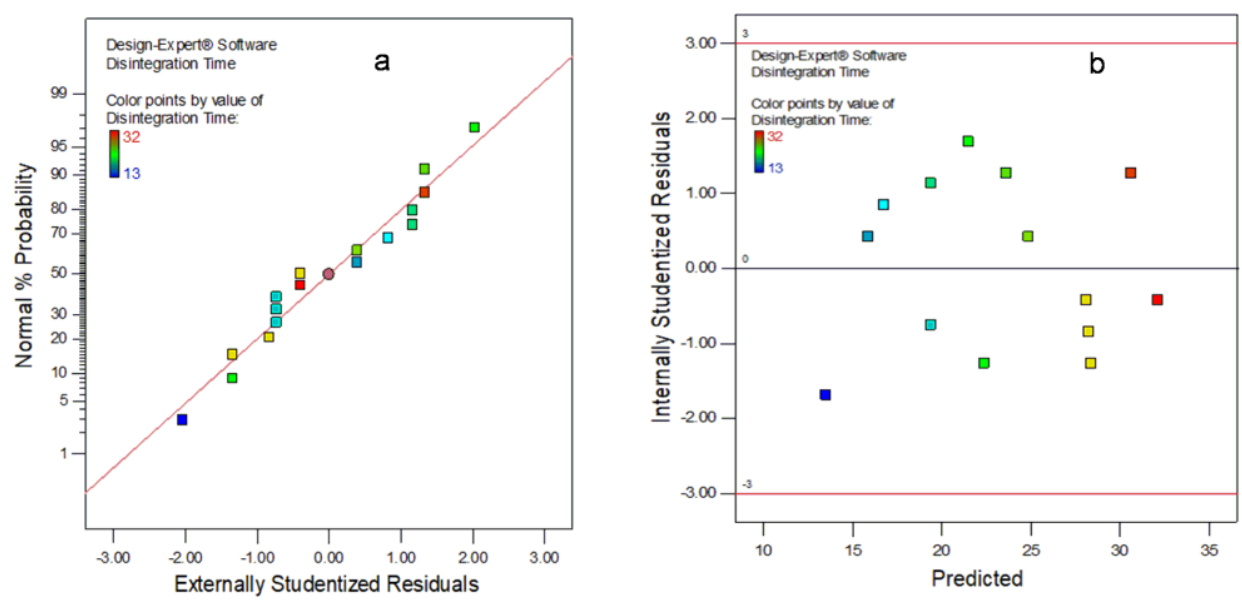

Fig. 1. (a) Normal probability plot of residuals and (b) internally studentized residual plot.

\subsection{Effect analysis}

The effect of an individual factor on the DT was visualized by one-factor effect graph (Fig. 2). It was found that L-HPC in a concentration around $3 \%(w / w)$ reduced the DT and above $4 \%$ the DT kept rising, indicating increasing binding property at higher 
concentration. CCS showed decreasing DT with increasing $\% \mathrm{w} / \mathrm{w}$ concentration and between $4 \%$ to $5 \%$ it reduced the DT at the most and, above $5 \%$ DT kept increasing indicating gel-forming properties of CCS at higher concentration. DT was reduced almost linearly with increasing punch dia.
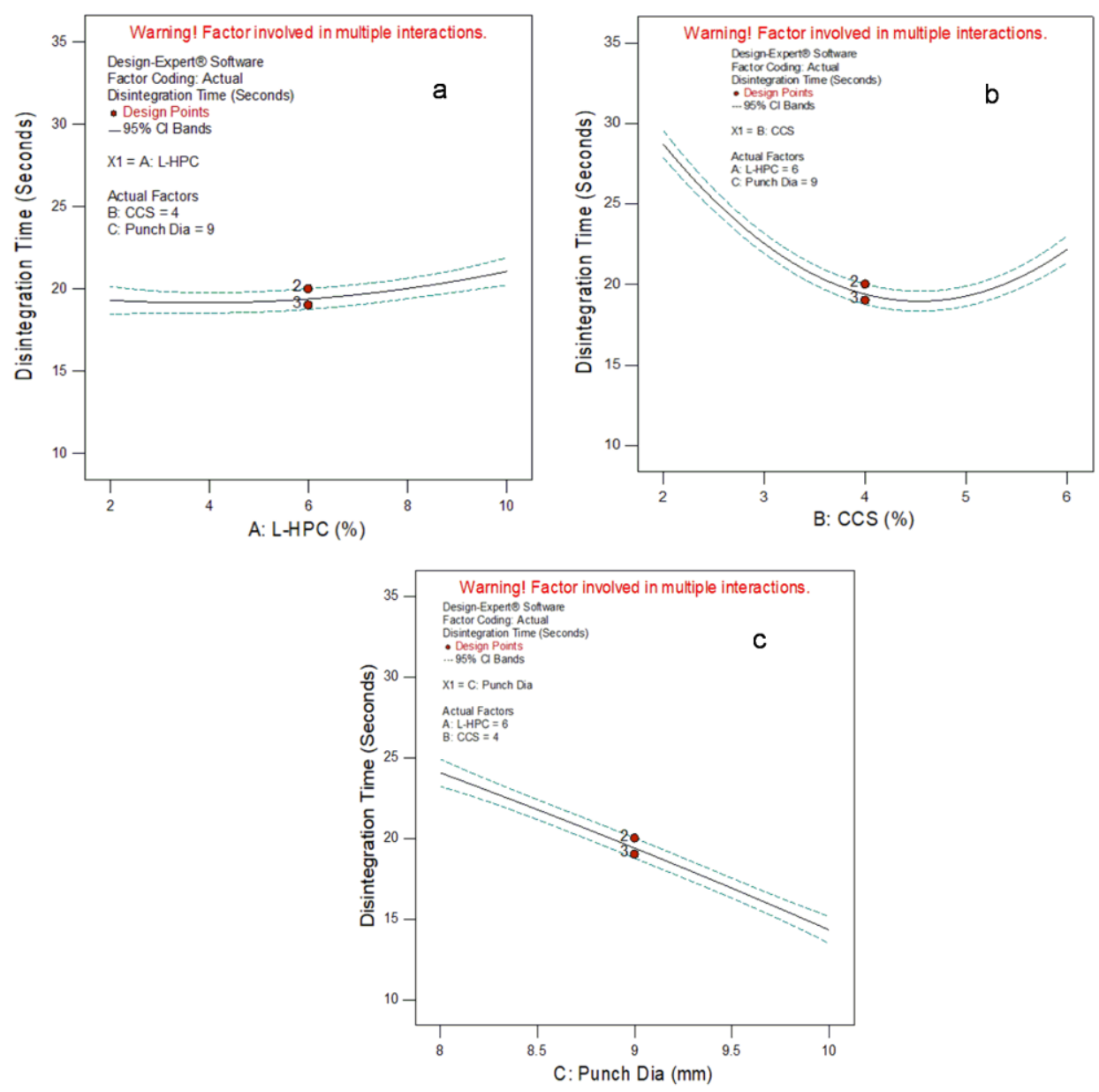

Fig. 2. Effects of (a) L-HPC alone, (b) CCS alone, and (c) punch dia alone on disintegration time.

\subsection{Design space}

Design space was constructed by overlaid contour plots to visualize the optimum condition for the desired formulation. In creating design space, the target of disintegration was constricted within $20 \mathrm{sec}$. At first, punch diameter was optimized using design space. It was found that a diameter below $8.6 \mathrm{~mm}$ produced no space for target DT regardless of any combination of CCS and L-HPC (Fig. 3). On the other hand, punch dia at $10.0 \mathrm{~mm}$ produced a wide space for meeting the target DT. But above $9.5 \mathrm{~mm}$, the thickness of 
tablets becomes too low with respect to the tablet weight $(220 \mathrm{mg})$ to handle in the subsequent process (e.g., blistering) and the friability of tablets having a diameter 10.0 $\mathrm{mm}$ was found close to a higher limit $(1.0 \%)$. Hence, the safe range was selected as 8.7 $\mathrm{mm}$ to $9.3 \mathrm{~mm}$ while the optimum was considered as $9.0 \mathrm{~mm}$.
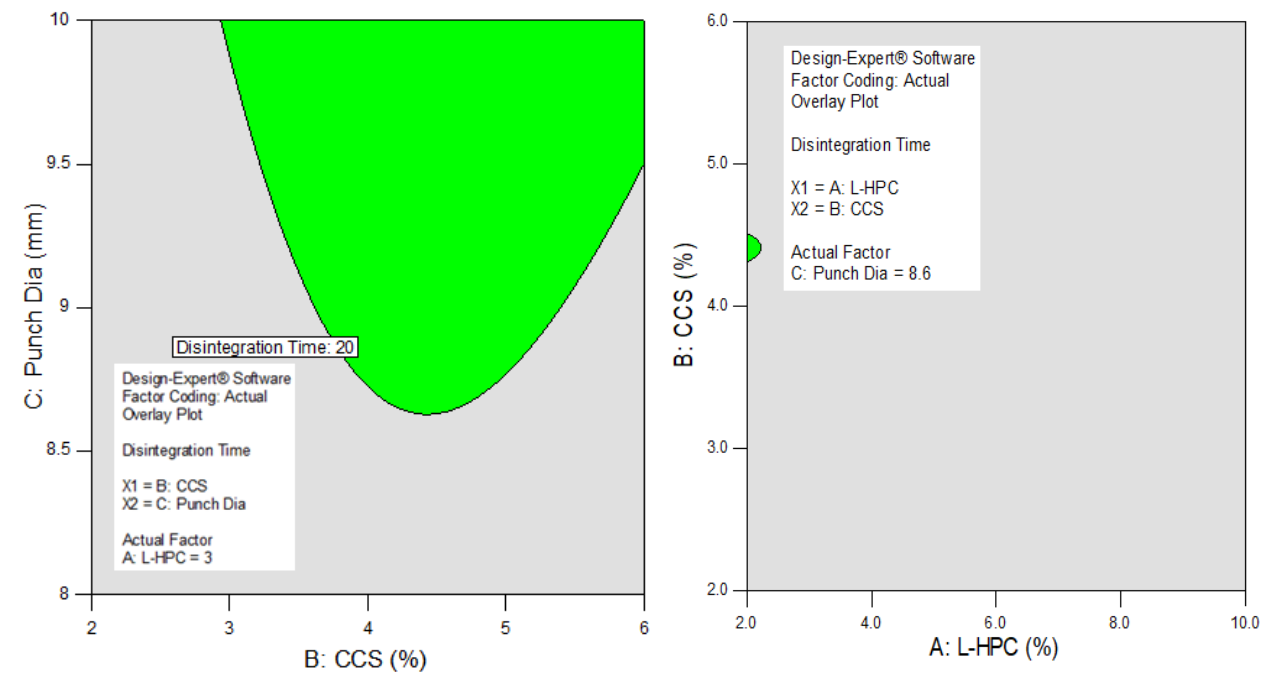

Fig. 3. Finding optimum punch dia in the design space.

Keeping the punch dia at $9.0 \mathrm{~mm}$ another overlay contour plot was constructed to create the design space and find the optimum concentration ranges of L-HPC and CCS. The design space was shown in Fig. 4. The green region indicated the design space where each point corresponds to a unique combination of L-HPC and CCS and formulation with any of those combinations meets the target DT. It was, therefore, obvious that within a punch diameter range of $8.7 \mathrm{~mm} \sim 9.0 \mathrm{~mm}$, L-HPC concentration range of $2 \% \sim 8 \% \mathrm{w} / \mathrm{w}$ and CCS concentration range of $4 \% \sim 5 \% \mathrm{w} / \mathrm{w}$, the risk of DT was reduced to the lower level as any combination of the factors in those ranges would result a DT of not more than $18 \mathrm{sec}$. which is much below of the initial target DT of $30 \mathrm{sec}$.

For the final formulation, \% w/w of L-HPC was chosen as $3.0 \%$ and that for CCS was chosen as $4.5 \%$ with a predicted DT of $18.79 \mathrm{sec}$ (with a confidence interval of 18.25 sec $19.33 \mathrm{sec}$ ) as shown in the Fig. 4. With this final composition, three small batches were prepared following the same manufacturing procedure and 10 tablets were collected from three stages: initial time of batch start, at the middle of the batch and towards the end of the batch. DT was checked using USP apparatus. Results were presented in Table 8. 


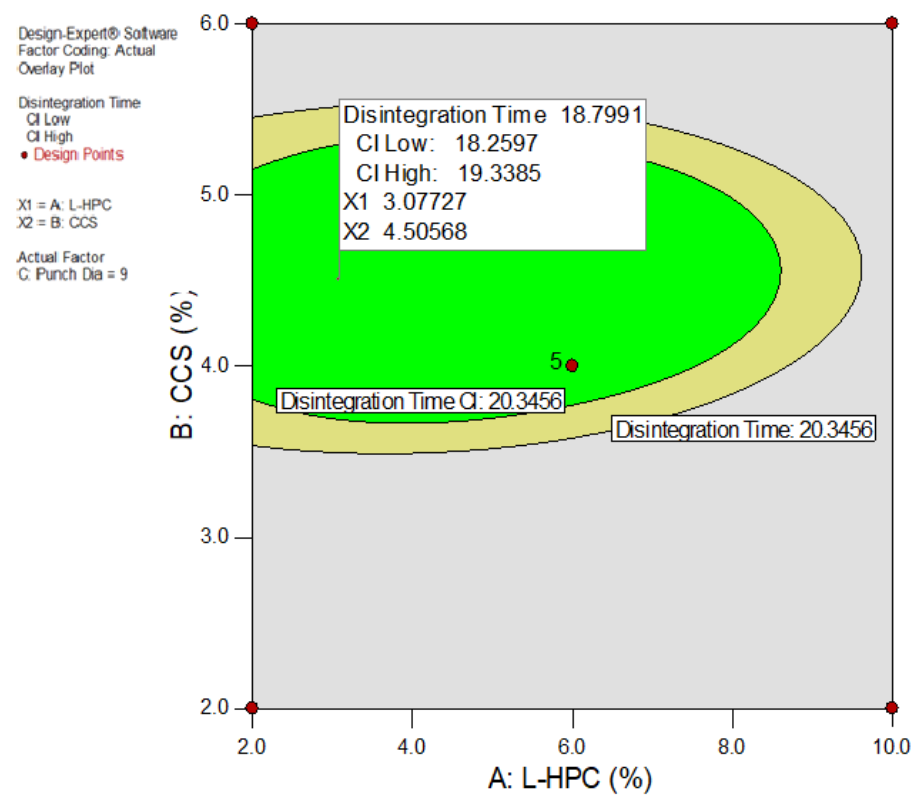

Fig. 4. Overlay contour plot and design space for optimum condition.

Table 8. Summary of disintegration time of three batches made following final composition.

\begin{tabular}{lllll}
\hline $\begin{array}{l}\text { Batch } \\
\text { No. }\end{array}$ & $\begin{array}{l}\text { DT of 10 tablets } \\
\text { from initial stage } \\
(\text { Mean } \pm \text { SD) }\end{array}$ & $\begin{array}{l}\text { DT of 10 tablets } \\
\text { from middle stage } \\
(\text { Mean } \pm \text { SD) }\end{array}$ & $\begin{array}{l}\text { DT of 10 tablets } \\
\text { from end stage } \\
(\text { Mean } \pm \text { SD) }\end{array}$ & $\begin{array}{l}\text { Mean DT } \pm \text { SEM } \\
(\mathrm{sec})\end{array}$ \\
\hline 1 & $18.9 \pm 1.37$ & $18.8 \pm 1.62$ & $18.2 \pm 1.69$ & $18.63 \pm 0.28$ \\
2 & $18.1 \pm 0.99$ & $18.7 \pm 1.42$ & $18.5 \pm 1.43$ & $18.43 \pm 0.23$ \\
3 & $18 \pm 1.33$ & $19.1 \pm 1.37$ & $18.9 \pm 1.6$ & $18.67 \pm 0.26$ \\
\hline
\end{tabular}

\subsection{Fine-tuning of final formulation and stability study}

The final quantitative composition having been fixed, hardness was optimized. All the optimization batches were compressed within a hardness limit of between 6 7 Kp. Two batches were prepared following the final formula and one was compressed to an average hardness of $5.0 \mathrm{Kp} \pm 0.5 \mathrm{Kp}$ and another was of $4.0 \mathrm{Kp} \pm 0.5 \mathrm{Kp}$ and friability was checked and found below $1 \%$. Tablets of the first batch disintegrated within $6 \mathrm{sec} \sim 7 \mathrm{sec}$ and tablets of the second batch disintegrated within $5 \mathrm{sec}$. Tablets from both batches were then packed in aluminum blister and loaded in accelerated stability conditions $\left(40{ }^{\circ} \mathrm{C}, 75 \%\right.$ relative humidity) and controlled conditions $\left(25^{\circ} \mathrm{C}, 60 \%\right.$ relative humidity) for the longterm stability study. After 3-months, hardness was found more or less the same as of initial condition in all conditions, but after 6-months, hardness was reduced by $1.0 \mathrm{Kp}$ for the first batch and by $1.5 \mathrm{Kp}$ for second batch on an average. Hardness was found above $3.0 \mathrm{Kp}$ for both batches (data not shown) in controlled condition at 12 months. Hence, the safe hardness limit during manufacturing should consider between $4.0 \sim 7.0 \mathrm{Kp}$. Assay of ASP was found as low as $92 \%$ at 6 months accelerated condition whereas in controlled 
condition assay was found to be $\sim 96 \%$ at 12 months. GLY was stable throughout all conditions. Hence, the preferred storage condition is $\leq 25^{\circ} \mathrm{C}$ in a dry place.

\section{Conclusion}

In the current study, QTPP and CQA were properly defined and CQAs were examined as a function of those critical formulation attributes and process attributes that were identified as medium to high risk by FMEA risk assessment. Optimization was successfully done through structured experimental design and statistical analysis. A design space was constructed to achieve a robust formula with a low risk for disintegration fail. From the study, it was concluded that an ODT dosage form of aspirin (100 mg) and glycine (45 mg) combination could be formulated in $220 \mathrm{mg}$ round tablet having any diameter between $8.7 \sim 9.3 \mathrm{~mm}$, comprising CCS in a range of $4 \% \sim 5 \%$ (w/w), preferably at $4.5 \%$ and L-HPC in a range of $2 \% \sim 8 \%(\mathrm{w} / \mathrm{w})$, preferably at $3 \%$ and within a hardness range of $4 \sim 7 \mathrm{Kp}$ for the best oral disintegrating property. Tablets with final composition contain a considerable amount of diluent (201.3 mg of MCC-101), meaning that other compliance agents like flavor/sweetener/ color (which works in minute percentage) can be added to this formulation without hampering the physical properties. In the end, it was an excellent example of $\mathrm{QbD}$ based formulation development process as per FDA guidelines for pharmaceutical industries.

\section{Acknowledgment}

The authors are very grateful to S. C. Das, General Manager of Beximco Pharmaceuticals Ltd, for providing all the materials (drugs and excipients) in this research.

\section{References}

1. J. G. Hardman, L. E. Limbird, and A. G. Gilman, Goodman \& Gilman's the Pharmacological Basis of Therapeutics. $10^{\text {th }}$ edition (McGraw-Hill Professional, New York, USA: McGraw-Hill Companies, 2001).

2. R. Finkel, M. A. Clark, and L. X. Cubeddu, Lippincott's Illustrated Reviews: Pharmacology, $4^{\text {th }}$ edition (2009).

3. W. Kusche, R. Paxinos, J. Haselmann, U. Schwantes, and H. K. Breddin, Advances in Therapy 20, 237 (2003). https://doi.org/10.1007/BF02849852

4. P. Müller, H. G. Dammann, H. Bergdolt, and B. Simon, Arzneimittelforschung. 41, 812 (1991).

5. H. D. C. Rapson, D. O. Singleton, A. C. E, Stuart, and M. P. Taylor, J. Pharm. Pharmacol. 11, 210 (1959). https://doi.org/10.1111/j.2042-7158.1959.tb10434.X

6. G. Murtaza, S. Karim, M. Najam-ul-Haq, M. Ahmad, T. Ismail, S. A. Khan, M. H. H. B. Asad, and I. Hussain, Acta Pol. Pharm. 71, 139 (2014).

7. S. Bandari, R. K. Mittapalli, R. Gannu, and Y. M. Rao, Asian J. Pharm. 2, 2 (2008). https://doi.org/10.4103/0973-8398.41557

8. M. S. Khan and M. S. Roberts, Adv. Drug Deliv. Rev. 135, 3 (2018). https://doi.org/10.1016/j.addr.2018.09.003

9. R. Pahwa, M. Piplani, P. C. Sharma, D. Kaushik, and S. Nanda, Arch. Appl. Sci. Res. 2, 35 (2010). 
10. T. Comoglu and E. D. Ozyilmaz, Pharm. Dev. Technol. 24, 902 (2019). https://doi.org/10.1080/10837450.2019.1615090

11. Guidance for Industry: Orally Disintegrating Tablets, U. S. Department of Health and Human Services Food and Drug Administration Center for Drug Evaluation and Research (CDER) (2008).

12. International Conference on Harmonisation of Technical Requirements for Registration of Pharmaceuticals for Human Use: Pharmaceutical Development Q8(R2) https://database.ich.org/sites/default/files/Q8_R2_Guideline.pdf (accessed on 5/29/2021)

13. Guidance for Industry: Q8(R2) Pharmaceutical Development, U.S. Department of Health and Human Services Food and Drug Administration Center for Drug Evaluation and Research (CDER) (2008).

14. D. C. Montgomery, Design and Analysis of Experiments, $5^{\text {th }}$ Ed. (John Wiley and Sons, 2004).

15. Starch $1500^{\circledast}$ Partially Pregelatinized Starch. Technical Bulletin of Colorcon. file:///C:/Users/kayes/AppData/Local/Temp/Tech\%20Bulletin_Starch1500_ranitidine-Final.pdf (Accessed on 5/29/2021).

16. C. Cunningham, B. R. Kinsey, and L. K. Scattergood, Pharm.Tech. 25, (2001).

17. R. C. Rowe, P. J. Sheskey, and M. E. Quinn, Handbook of Pharmaceutical Excipients (Pharmaceutical Press and American Pharmacists Association, 2009)

18. K. A. Connors, G. L. Amidon, and V. J. Stella, Chemical Stability of Pharmaceuticals: A Handbook for Pharmacists (Wiley, New York, 1986).

19. P. V. Mroso, A. L. Wan Po, and W. J. Irwin, J. Pharm. Sci. 71, 1096 (1982). https://doi.org/10.1002/jps.2600711004

20. J. Li and Y. Wu, Lubricants 2, 21 (2014). https://doi.org/10.3390/lubricants2010021

21. C. Ahlneck, J. O. Waltersson, and P. Lundgren, Acta Pharm. Technol. 33, 21 (1987).

22. S. S. Kornblum and M. A. Zoglio, J. Pharm. Sci. 56, 1569 (1967). https://doi.org/10.1002/jps.2600561208

23. H. V. van Kamp, G. K. Bolhuis, K. D. Kussendrager, and C. F. Lerk, Int. J. Pharm. 28, 229 (1986). https://doi.org/10.1016/0378-5173(86)90249-8

24. C. Chebli and L. Cartilier, Int. J. Pharm. 171, 101 (1998). https://doi.org/10.1016/S0378-5173(98)00161-6

25. F. Ferrari, M. Bertoni, M. C. Bonferoni, S. Rossi, C. Caramella, and C. Nyström, Int. J. Pharm. 136, 71 (1996). https://doi.org/10.1016/0378-5173(96)04489-4

26. S. Mattsson, S. Bredenberg, and C. Nyström, S.T.P. Pharma Sci. 11, 211 (2001).

27. G. K. Bolhuis and N. A. Armstrong, Pharm. Dev. Technol. 11, 111 (2006). https://doi.org/10.1080/10837450500464255

28. C. F. Lerk, G. K. Bolhuis, and A. H. de Boer, J. Pharm. Sci. 68, 205 (1979). https://doi.org/10.1002/jps.2600680222

29. Shin-Etsu Technical Bulletin of L-HPC. https://www.chemlink.co.uk/wp-content/uploads/2014/05/Shin-EtsuLHPC_20140903.pdf (Accessed on 5/29/2021)

30. M. Soundaranathan, P. Vivattanaseth, E. Walsh, K. Pitt, B. Johnston, and D. Mark, Int. J. Pharm. 590, 119903 (2020). https://doi.org/10.1016/j.ijpharm.2020.119903

31. N. Zhao and L.L. Augsburger, AAPS Pharm. Sci. Tech. 6, 79 (2005). https://doi.org/10.1208/pt060479

32. J. Zhao, O. Koo, D. Pan, Y. Wu, D. Morkhade, S. Rana, P. Saha, and A. Marin, AAPS J. 19, 1387 (2017). https://doi.org/10.1208/s12248-017-0104-6

33. M. R. Nazareth, and C. L. Huyck, J. Pharm. Sci. 50, 620 (1961). https://doi.org/10.1002/jps.2600500721

34. T. Abe, Y. Yanagihara, T. Uchino, T. Oriyama, M. Komatsu, K. Nakajima, and H. Suzuki, Chem. Pharm. Bull. 62, 617 (2014). https://doi.org/10.1248/cpb.c13-00580

35. S. S. Dawoodbhai, H. R. Chueh, and C. T. Rhodes, Drug Dev. Ind. Pharm. 13, 2441 (1987). https://doi.org/10.3109/03639048709020596 